\title{
Congenital Lobar Emphysema Diagnosed in Adult Age: A Case Report
}

\section{Tayfun Çalışkan, Oğuzhan Okutan, Faruk Çiftçi, Zafer Kartaloğlu, Dilaver Taş, Ersin Demirer}

\author{
Department of Pulmonology, Haydarpaşa Training Hospital, Gülhane Military Medical Academy, İstanbul
}

\begin{abstract}
Congenital Lobar Emphysema (CLE) is a rare congenital pulmonary malformation and it is characterized by hyperinflation of one or more lobes of the lungs. The disease is usually encountered in infants aged less than 6 months and it is very rare in adulthood. Herein, we presented a patient with CLE, who received asthma treatment for dyspnoea complaint in adult age but was switched to anxiolytic medications as no benefit was achieved from asthma treatment. The diagnosis of the patient was made clinically, radiologically and scintigraphycally. Although it is a rarely encountered condition, CLE should be considered among the prediagnosis, in patients with localized unilateral hyperinflation on chest $\mathrm{x}$-ray, presenting with dyspnoea in adult age.
\end{abstract}

Keywords: Adult, congenital lobar emphysema, dyspnoea

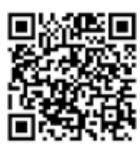

Received date: 09.01 .2012 Accepted date: 03.04 .2012

\section{Address for correspondence}

Tayfun Çalışkan, Department of Pulmonology, Haydarpaşa Training Hospital, Gülhane Military

Medical Academy, İstanbul, Turkey

E-mail: drtcaliskan@yahoo.com

(C) Copyright 2014 Turkish Respiratory Society (TRS) DOI: 10.5152/ejp.2014.27136

- Available online at www.eurasianjpulmonol.com

\section{INTRODUCTION}

Congenital Lobar Emphysema (CLE) was first defined in 1932 by Nelson (1). CLE is a rarely encountered congenital developmental anomaly of the lungs and it is characterized by compression of adjacent lung tissue and displacement of the mediastinum towards the opposite side together with hyperinflation of one lung lobe. The prevalence of congenital lobar emphysema has been reported to be $1 / 20,000-30,000$ (2). Airway obstruction is the most common cause of the disease, but the cause of the disease cannot be detected in $25 \%$ of the patients. It manifests with progressive dyspnoea and tachypnea a few days after birth in more than half of the cases (3-5). It is more prevalent among males (6) with an $\mathrm{M} / \mathrm{F}$ ratio of $3 / 1$. A consolidation area is seen on the chest $\mathrm{x}$-ray of new-borns with respiratory distress, performed just after birth. The diagnosis is usually made clinically, radiologically and scintigraphycally. The traditional treatment of the disease is surgical (lobectomy) (7); however, conservative treatment is also being recommended in the recent years (8). A few cases, which were diagnosed at adult age, have been reported in the literature $(9,10)$. Herein, we presented a patient with congenital lobar emphysema diagnosed in adult age, in which bronchial asthma treatment was started, but replaced with anxiolytic medications as asthma treatment provided no benefit.

\section{CASE PRESENTATION}

A 20-year-old male patient was admitted to our clinic with shortness of breath, chest pain, frequent urination and increased appetite. He had dyspnoea for 7 years, and was started on short-acting bronchodilator therapy after being diagnosed with bronchial asthma 5 years ago. The patient complained about frequent respiratory infections. He had been hospitalized in a state hospital as his complaints worsened and treated for bronchial asthma and pneumonia approximately one month ago. Since his complaints persisted despite treatment over the course of hospital stay, he had been consulted with psychiatry, and with a prediagnosis of psychogenic dyspnoea, he was started on antidepressant thera- 


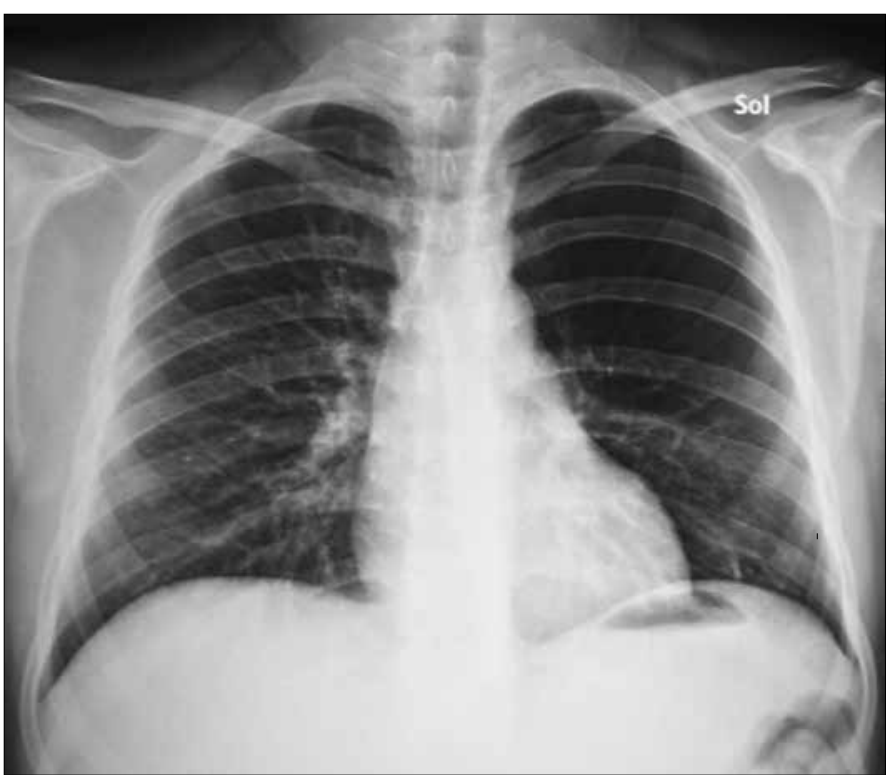

Figure 1. Postero-anterior chest $x$-ray of the patient showing hyperinflation in the upper and middle zones of the left lung.

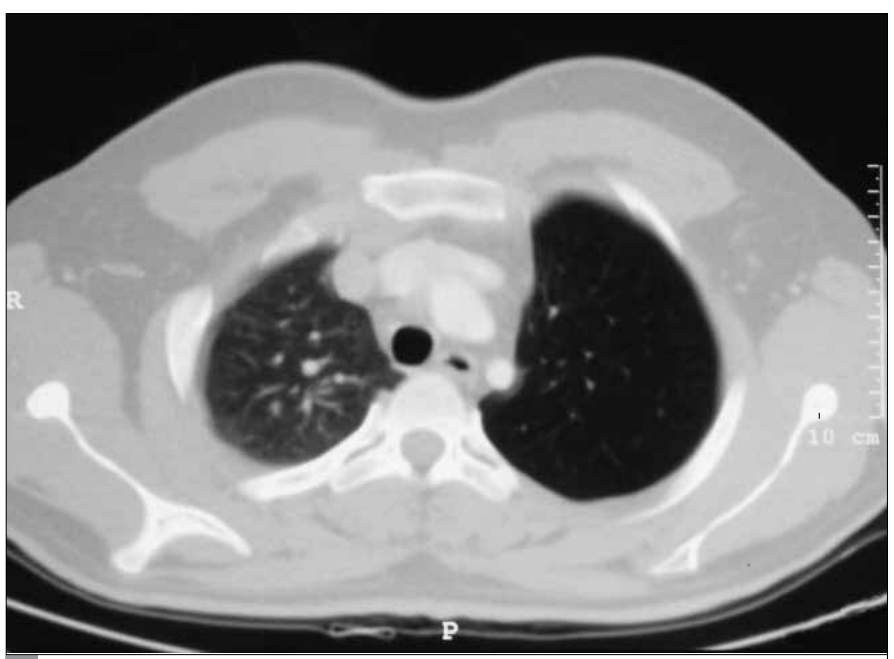

Figure 2. Computed tomographic angiography of thorax; prominent hyperinflation in the upper lobe of the left lung except for lingular segment, mild peribronchial thickening particularly in the central aspects of both lungs.

py. His medical history revealed appendectomy and anxiety disorder. His family history was unremarkable. He had 7 packs.year smoking history. On his physical examination, he was conscious, oriented and cooperated, his blood pressure was $120 / 70 \mathrm{mmHg}$, pulse rate was 80 / min, body temperature was $36^{\circ} \mathrm{C}$, and oxygen saturation was $98 \%$ in room air. Respiratory system examination revealed decreased thoracic vibration in the subscapular area of the left hemithorax on palpation; hypersonority on percussion; and decreased breath sounds on auscultation. White blood cell count (WBC) was $15.800 / \mathrm{mm}^{3}$, haemoglobin $(\mathrm{Hb})$ was $15.2 \mathrm{gr} / \mathrm{dL}$, haematocrit $(\mathrm{Htc})$ was $43.7 \%$, and platelet count (PIt) was $275,000 / \mathrm{mm}^{3}$, and his fasting blood glucose concentration was high. Endocrinology consultation was requested and treatment was started for diabetes mellitus. Serum alpha-1 antitrypsin concentration was normal. The results of pulmonary function tests were as follows; FVC: $88.3 \%$, FEV 1 : 80.9\%, FEV /FVC: $93.5 \%$, PEF:

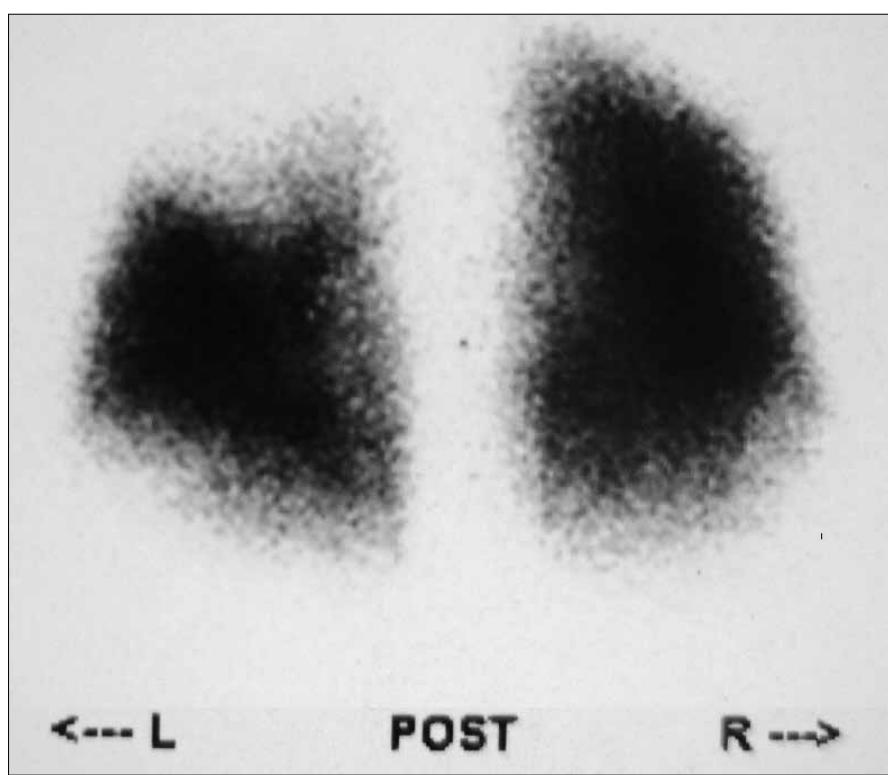

Figure 3. Perfusion scintigraphy of the patient; perfusion defects were observed in the upper lobe of the left lung.

58.8\%, and MMEF 25-75\%: 62.1\%; reversibility test was positive. His chest $\mathrm{x}$-ray demonstrated hyperinflation in the upper and middle zones of the left lung (Figure 1). Antibiotics and mucolytic medications were given to the patient.

Computed tomographic (CT) angiography of thorax demonstrated prominent hyperinflation in the upper lobe of the left lung, except for lingular segment, mild peribronchial thickening particularly in the central regions of the lower zones of both lungs, and no abnormality in the vascular configurations (Figure 2).

The patient underwent bronchoscopy. On bronchoscopic examination, the orifice of the left upper lobe showed fusiform narrowing. When the fiberoptic bronchoscope (FOB) was advanced, it was observed that lingula and orifices of upper division segments were open and there was no endobronchial lesion. Perfusion scintigraphy revealed perfusion defects in the left upper lobe (Figure 3). Cardiology consultation was made and echocardiography was performed; no concomitant cardiovascular pathology was determined. The patient was taken to follow-up under conservative treatment.

\section{DISCUSSION}

Congenital lobar emphysema is a rarely encountered developmental anomaly of the lung and it is characterized by pulmonary hyperinflation. It is also named as infantile lobar emphysema. In the new nomenclature, the term 'congenital large hyperlucent lobe' is used (11). It is seen within the first 6 months of birth or earlier in $95 \%$ of the patients. The disease appears within hours after birth in $1 / 3$ and within months in $50 \%$ of the patients. The majority of the patients are diagnosed until the $6^{\text {th }}$ month of life (2). In the literature, there are a few cases diagnosed in adult age $(9,10)$. Therefore, the present case being an adult at the age of 20 years is an interesting characteristic.

The disease is more prevalent among males, and the present case was also a male patient. The disease is located in the left upper lobe by $40-50 \%$, right middle lobe by $25-35 \%$, and right upper lobe by $20 \%$ (12). In the present case, the disease was localized in the upper 
lobe of the left lung. The disease occurs due to bronchopulmonary developmental anomaly. No cause can be identified in $50 \%$ of patients; the most common cause is airway obstruction found in $25 \%$ of patients. Airway obstruction may either be extrinsic or intrinsic and subsequently air-trapping occurs due to 'balloon-valve' mechanism. Intrinsic causes include bronchial wall defects such as absence of bronchial cartilage, as well as bronchial atresia, bronchial stenosis, bronchomalacia, meconium, foreign bodies, mucus plaques, and granulomas. Extrinsic causes include vascular anomalies and intrathoracic masses such as teratoma. Histopathologically, the disease does not involve true emphysematous changes. The disease, therefore, has been named as congenital hyperinflation or congenital lobar hyperinflation in addition to CLE. In polyalveolar form, alveoli are enlarged and increased in number (2).

The disease is generally seen in the neonatal period and patients are usually asymptomatic (3-6). Progressive respiratory distress occurs in hours or sometimes in days after birth. Dyspnoea, tachypnea, cyanosis, increase in respiratory work, chest retraction, wheezing and cough are symptoms detected in infants. Recurrent pneumonia and malnutrition may be seen. On physical examination, breath sounds are decreased in the regions consistent with the disease, as was in the present patient case, and hypersonority is detected on percussion.

Although obstructive respiratory disorder was not found in the pulmonary function tests of our patient, his reversibility test was positive. Asthma was not considered in the patient based on his anamnesis, physical examination and his clinical picture, and also because of the failure of previous asthma treatment; thus, asthma medications were not given. No asthma findings were detected in his follow-up during hospital stay and on control visit after two months.

Chest $\mathrm{x}$-ray has a critical importance in the diagnosis of disease. Chest $\mathrm{x}$-ray illustrates hyperlucency in the zone consistent with the involved lobe of the lung, mediastinal displacement to the opposite lung, compression and atelectasis in the opposite lung, and diaphragmatic flattening on the same side. If chest $x$-ray is performed just after birth, opacities instead of hyperinflation may be seen. Computed tomography is used both for diagnosis in patients in which chest $x$-ray is not diagnostic and also to propound the reason for extrinsic or intrinsic airway obstruction. Bronchoscopy is performed to determine the likely causes of airway obstruction in patients. In the present case, bronchoscopy revealed fusiform narrowing in the orifice of the right upper lobe; however, when FOB was advanced, it was observed that segment orifices were patent. We suggest that this case resulted from the developmental disorder of cartilage, which is among the etiological factors of CLE. Thoracic CT angiography showed no abnormality concerning the cause of disease. Echocardiography is used to demonstrate cardiovascular anomalies that accompany the disease by $14 \%$ and vascular reasons that lead to airway compression (13). Cardiovascular abnormalities are the most common accompanying congenital anomalies; but renal, gastrointestinal, musculoskeletal system and dermatological anomalies may also be encountered. Cardiology consultation was requested for the patient, and echocardiography was performed; no concomitant cardiovascular anomaly was detected. In congenital lobar emphysema, ventilation/perfusion scintigraphy demonstrates decreased ventilation and perfusion in the involved lobe. The present patient case underwent only perfusion scintigraphy, which showed perfusion defects in the upper lobe of the left lung. There are cases diagnosed by ultrasonography in the perinatal period (14). Perinatal ultrasonography may demonstrate pulmonary lesions that show increased echogenicity and/or appear as cystic lesions.

Congenital lobar emphysema can be mixed up with many diseases that cause localized hyperinflation. Moreover, differential diagnosis includes pneumothorax, congenital pulmonary airway malformation, congenital adenomatoid malformation, bronchopulmonary sequestration, bronchogenic cyst, congenital diaphragmatic hernia, isolated unilateral absence of pulmonary artery, and Swyer-JamesMacLeod syndrome. Swyer-James-MacLeod syndrome is characterized by decreased pulmonary vascularity (hypoplastic pulmonary artery) and hyperinflation; patients are usually asymptomatic and unilateral hyperlucent lung is observed (15). No pulmonary vascular abnormality was detected on thoracic CT angiography of the present case. In case of unilateral absence of pulmonary artery, perfusion is observed due to collaterals in the peripheral aspect of the lung at the site pulmonary artery is absent (16).

Lobectomy is recommended for treatment particularly in patients with respiratory distress in neonatal period, with symptomatic worsening and with chronic and/or recurrent infections (4-7). In the recent years, surgical resection via thoracoscopy is also being performed as an alternative to thoracotomy (17). Conservative treatment is recommended for asymptomatic or minimally symptomatic patients $(3,8,18)$. We, as well, performed conservative treatment instead of surgery.

\section{CONCLUSION}

Although it is a rare condition in adults, CLE must be among the prediagnosis that should be considered in patients with localized hyperinflation on chest $\mathrm{x}$-ray, presenting with dyspnoea in adult age.

Informed Consent: Written informed consent was obtained from patient who participated in this case.

Peer-review: Externally peer-reviewed.

Author contributions: Concept - T.Ç., O.O.; Design - F.Ç., Z.K.; Supervision -T.Ç., F.Ç.; Resource - O.O., T.Ç.; Materials - Z.K., D.T.; Data Collection\&/or Processing - D.T., E.D.; Analysis\&/or Interpretation - Z.K., F.Ç.; Literature Search - T.Ç., E.D.; Writing - T.Ç., O.O.; Critical Reviews - D.T., E.D.

Conflict of Interest: No conflict of interest was declared by the authors.

Financial Disclosure: The authors declared that this study has received no financial support.

\section{REFERENCES}

1. RL. Congenital cystic disease of the lung: Report of a case. J Pediatr 1932; 1: 233-38. [CrossRef]

2. Dakshesh H. Parikh, David CG. Crabbe, Alexendar W. Auldist, Steven S. Rothenberg. Pediatric Thoracic Surgery. London: Springer-Verlag Limited; 2009.p.407-10.

3. Ozçelik U, Göçmen A, Kiper N, Doğru D, Dilber E, Yalçin EG. Congenital lobar emphysema: evaluation and long-term follow-up of thirty cases at a single center. Pediatr Pulmonol 2003; 35: 384-91. [CrossRef]

4. Thakral CL, Maji DC, Sajwani MJ. Congenital lobar emphysema: experience with 21 cases. Pediatr Surg Int 2001; 17: 88-91. [CrossRef] 
5. Tander B, Yalçin M, Yilmaz B, Ali Karadağ C, Bulut M. Congenital lobar emphysema: a clinicopathologic evaluation of 14 cases. Eur J Pediatr Surg 2003; 13: 108-11. [CrossRef]

6. Nazem M, Hosseinpour M. Evaluation of early and late complications in patients with congenital lobar emphysema: a 12 year experience. Afr J Paediatr Surg 2010; 7: 144-6. [CrossRef]

7. Dogan R, Demircin M, Sarigul A, Paşaoğlu I, Göçmen A, Bozer AY. Surgical management of congenital lobar emphysema. Turk J Pediatr 1997; 39: 35-44.

8. Ceran S, Altuntas B, Sunam GS, Bulut I. Congenital lobar emphysema: is surgery routinely necessary? Afr J Paediatr Surg 2010; 7: 36-7. [CrossRef]

9. Sadaqat $M$, Malik JA, Karim R. Congenital lobar emphysema in an adult. Lung India. 2011; 28: 67-9. [CrossRef]

10. Canneto B, Carretta A, Vagani A, Puglisi A, Pansera M, Zannini P. Congenital lobar emphysema in adults. Minerva Chir 2000; 55: 353-6.

11. Kendig's Disorders of Respiratory Tract in Children. Philadelphia: Saunders Elsevier; 2006.p.301-3.
12. Mendeloff EN. Sequestrations, congenital cystic adenomatoid malformations, and congenital lobar emphysema. Semin Thorac Cardiovasc Surg 2004; 16: 209-14. [CrossRef]

13. Moideen I, Nair SG, Cherian A, Rao SG. Congenital lobar emphysema associated with congenital heart disease. J Cardiothorac Vasc Anesth 2006; 20: 239-41. [CrossRef]

14. Babu R, Kyle P, Spicer RD. Prenatal sonographic features of congenital lobar emphysema. Fetal Diagn Ther 2001; 16: 200-2. [CrossRef]

15. Capela C, Gouveia P, Sousa M, Regadas MJ. Adult diagnosis of Swyer-JamesMacLeod syndrome: a case report. J Med Case Reports 2011; 5: 2. [CrossRef]

16. Okutan O, Ugan H, Kaya H, Taş D, Demirer E, Apaydın M, Çalışkan T. Isolated unilateral absence of pulmonary artery: a case report. Turkish Journal of Thoracic and Cardiovascular Surgery 2010; 18: 67-70.

17. Granato F, Voltolini L, Spina D,Paladini P, Gallazzi M, Gotti G. VATS for congenital lobar emphysema: a case report. Minerva Chir 2009; 64: 111-5.

18. Ulku R, Onat S, Ozçelik C. Congenital lobar emphysema: differential diagnosis and therapeutic approach. Pediatr Int 2008; 50: 658-61. [CrossRef] 